\title{
Analysis of Residual Stress Relaxation Under Mechanical Cyclic Loading of Shot-Peened TRIP780 Steel
}

\author{
Clément Mauduit ${ }^{1,2^{*}}$, Régis Kubler ${ }^{2}$, Laurent Barrallier ${ }^{2}$, Sophie Berveiller ${ }^{3}$, \\ Quentin Puydt ${ }^{1}$, Martine Monin ${ }^{4}$, Bastien Weber ${ }^{5}$ \\ ${ }^{1}$ IRT M2P, 4 Rue Augustin Fresnel, 57078 Metz, France \\ ${ }^{2}$ MSMP, Arts et Métiers ParisTech, 2 Cours des Arts et Métiers, 13617 Aix en Provence, France \\ ${ }^{3}$ LEM3, Arts et Métiers ParisTech, 4 Rue Augustin Fresnel, 57070 Metz, France \\ ${ }^{4}$ PSA, 18 Rue des Fauvelles, 92250 La Garenne Colombes, France \\ ${ }^{5}$ ArcelorMittal, Voie Romaine, 57280 Maizières-lès-Metz, France
}

Keywords: TRIP Steel, Shot-Peening, Residual Stresses, Relaxation

\begin{abstract}
Shot-peening is a common mechanical surface treatment used in automotive and aeronautical industries to enhance life duration of mechanical parts by introducing compressive residual stresses. TRIP 780 steel fatigue type specimens are shot-peened and loaded under cyclic bending. The martensite phase transformation and the evolution of residual stresses in the different phases are determined by XRD at different numbers of cycles. A FEM model is also proposed to better understand the evolution of residual stresses in the first cycles.
\end{abstract}

\section{Introduction}

Most surface treatments aim at enhancing life duration of mechanical parts by introducing compressive residual stresses. Shot-peening (SP) process generates a compressive residual stress by deformation of the surface which is accommodated by elastic residual strains. However, those induced stresses may not be stable during the life of a part submitted to thermal and mechanical fatigue. This study deals with the analysis of mechanical stress relaxation and microstructure evolutions of a TRIP-aided steel, TRIP780 [1, 2], after shot peening and subsequent cyclic mechanical loading. This steel exhibits a multiphase microstructure (ferrite, bainite, and austenite) where each mechanical constituent participates to the global behavior [3,4]. Austenite is a metastable phase which can transform into martensite under a thermomechanical loading.

To reach this goal, the mechanisms responsible for relaxation (plasticity, phase transformation) have to be identified. The first part presents the experimental set-up of the performed analysis and the obtained results are presented and discussed. In a second part, a FEM model using a phenomenological approach is presented in order to understand the redistribution of mechanical fields (macroscopic stress and plastic strain) during the first cycles.

\section{Experimental methods}

TRIP780 steel exhibits a multiphase microstructure (austenite, bainite and ferrite). Its chemical composition is given in Table 1 . The volume fraction of initial austenite is about $13 \%$ with $70 \%$ of ferrite and $17 \%$ of bainite. The macroscopic yield strength of TRIP780 steel provided by ArcelorMittal is $560 \mathrm{MPa}$.

Standard fatigue type specimens cut in the transverse direction (TD) of a $2 \mathrm{~mm}$ thick TRIP780 steel sheet (Fig. 1) are submitted to cyclic bending.

\begin{tabular}{|c|c|c|c|}
\hline $\mathrm{C}$ & $\mathrm{Mn}$ & $\mathrm{Si}$ & $\mathrm{Fe}$ \\
\hline 0.21 & 1.6 & 1.6 & Bal. \\
\hline
\end{tabular}

Table 1 Chemical composition of TRIP780 steel in \% wt (iron balanced) 

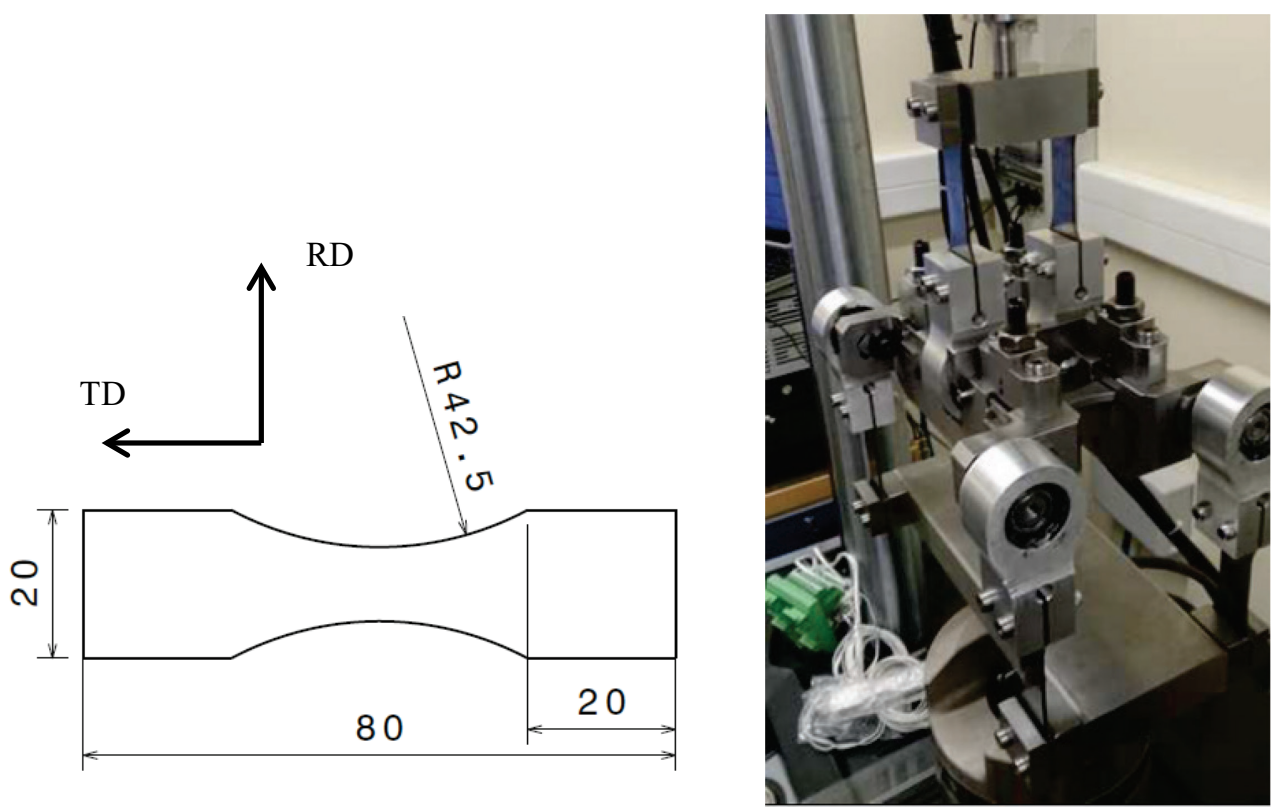

Figure 1 Specimen geometry (a). Thickness $2 \mathrm{~mm}$. Dimensions in $\mathrm{mm}$. Bending test bench (b)

Specimens are shot-peened in a turbine Wheelabrator machine successively on each face. The Almen intensity is F19A. The shot-peening conditions are as following: $400 \mu \mathrm{m}$ diameter conditioned cut wire shots- hardness $700 \mathrm{HV}$, coverage $230 \%$. The resulting Ra roughness is $4.5 \mu \mathrm{m}$.

The specimens are submitted to cyclic reverse bending $(\mathrm{R}=-1)$ with an imposed curvature which leads to pure bending in the area of interest. The bending test bench was developed for this study by the academic and industrial partners (Fig. 1b). The residual stresses are determined at 3 interrupted states (initial, 1000 and half-life cycles) with three targeted loading intensities $(585,600$ and 650 $\mathrm{MPa}$ at the surface). Bending loads are calculated and calibrated from a pure elastic behavior.

Residual stresses are determined in austenite (FCC) and ferritic constituents (CC and BCC) using $\mathrm{X}$ ray diffraction (XRD) analysis with $\sin ^{2} \psi$ method [5]. A D500 Siemens XRD goniometer is used to determined stress in ferritic constituents (ferrite, bainite and martensite) with $\mathrm{Cr}$ radiation and Vanadium filter on the $\{211\}$ planes with $40 \mathrm{kV}$ and $30 \mathrm{~mA}$. The austenite fraction determination is carried out on the same apparatus following the ASTM standards [6]. When more than 5\% of austenite is detected, residual stresses in the austenitic phase are determined with an Elphyse Set-X machine using $\mathrm{Mn}$ radiation with $\mathrm{Cr}$ filter on the $\{311\}$ planes. Residual stresses profiles are obtained by electropolishing in the transverse direction. Since the specimens are $2 \mathrm{~mm}$ thick, the determined stresses are corrected taking into account the layer removal [7].

\section{Experimental results}

After shot-peening, the retained austenite has transformed to martensite and a gradient of martensite and residual stresses in the specimen is determined. Figure 2 presents the austenite fraction profile after SP. Associated stress profiles of ferritic and austenitic phases are displayed in Figure 3 . The determined stress in each constituent $\varphi$ represents the quantity $\sigma_{\mathrm{xx}}^{\varphi}-\sigma_{\mathrm{zz}}^{\varphi}$, with the macroscopic value $\sigma_{\mathrm{zz}}^{\text {Macro }}$ being equal to zero for a uniform shot peening treatment.

With $13 \%$ austenite in the as-received material, we assume that austenite is transformed in the first $200 \mu \mathrm{m}$. At surface, the assumption can be made that austenite is totally transformed. The shotpeened specimens show a maximum stress in compression of $-600 \mathrm{MPa}$ in ferritic constituent and $600 \mathrm{MPa}$ in austenite phase too. As the detection threshold of austenite is 5\%, residual stresses determination is carried out from $70 \mu \mathrm{m}$ 


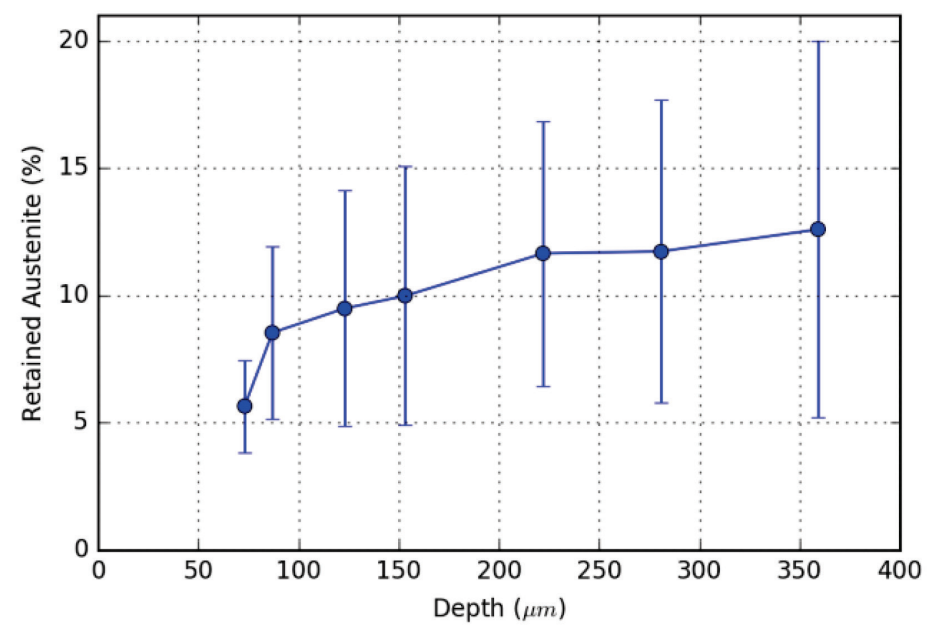

Figure 2 Initial retained austenite profile after $S P$
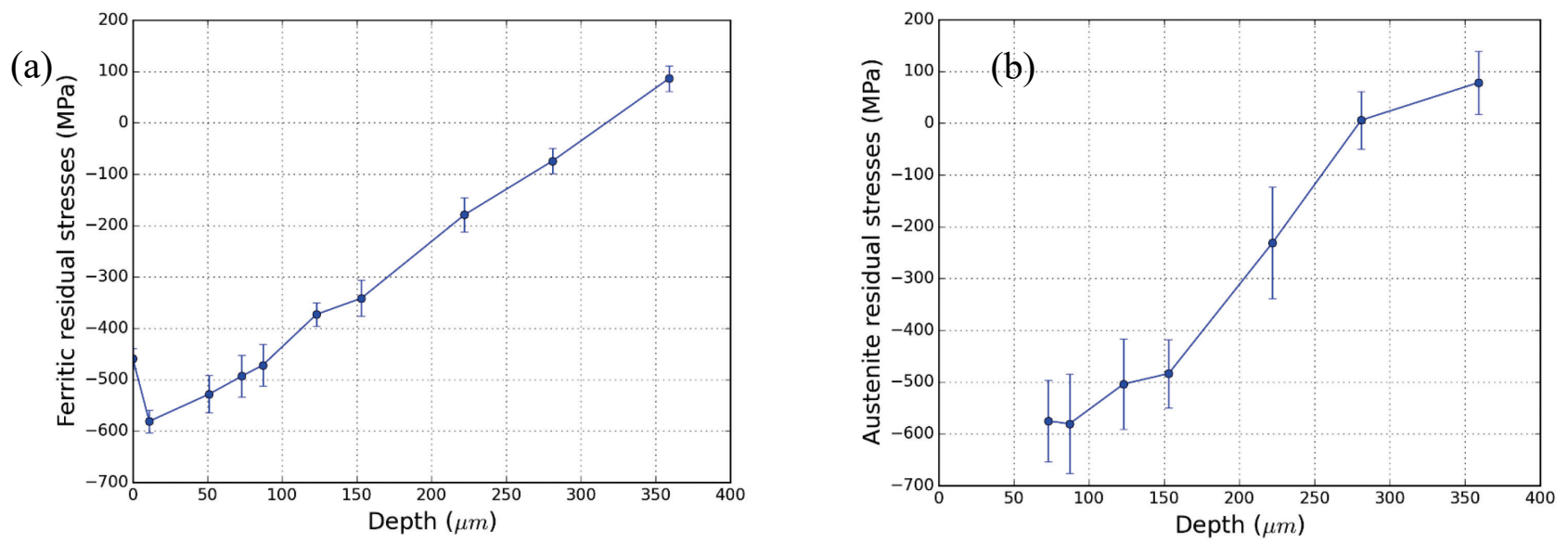

Figure 3 Corrected residual stress profiles after SP (a) in ferritic constituents, (b) in austenite in the transverse direction

In the following part, the focus is made on the macroscopic stress $\sigma_{\text {macro }}(z)$ at each depth $z$ in the material, resulting from the averaging of the stresses in austenite $\sigma_{x x}^{\text {aust }}$ and ferritic $\sigma_{x x}^{\text {ferr }}$ constituents by a mixture law:

$$
\sigma_{x x}^{\text {Macro }}(z)=f^{\text {aust }} \cdot \sigma_{x x}^{\text {aust }}(z)+\left(1-f^{\text {aust }}\right) \sigma_{x}^{\text {ferr }}(z)
$$

where $f^{\text {aust }}$ is the austenite volume fraction determined by XRD and $x$ is the measurement direction (TD in this case).

During the cyclic tests, SP specimens are submitted to an imposed curvature at 3 loads $(585,600$ and $650 \mathrm{MPa}$ at the surface). In Figure 4, residual macroscopic stresses after 0, 1000 and half-life cycles under the 3 loads are displayed. For the highest loading of $650 \mathrm{MPa}$ (Figure 4a), residual stresses relax mainly in the first thousand cycles. The relaxation still takes place between 1000 and half-life cycles. For 600 and $585 \mathrm{MPa}$ (Figure $4 \mathrm{~b}$ and 4c respectively), relaxation in the subsurface 
appears to be more important than at the surface. For each profile except $650 \mathrm{MPa}$, residual stresses reach a level of $-50 \mathrm{MPa}$ in subsurface (after $100 \mu \mathrm{m}$ depth), and reach $-300 \mathrm{MPa}$ at the surface. For $600 \mathrm{MPa}$ and $585 \mathrm{MPa}$, profiles cross at $300 \mu \mathrm{m}$ at the value of $0 \mathrm{MPa}$. The relaxation behavior seems to be different in the first 50-100 $\mu \mathrm{m}$ than in the rest of the sample. It corresponds with the zone where austenite has been transformed by SP.
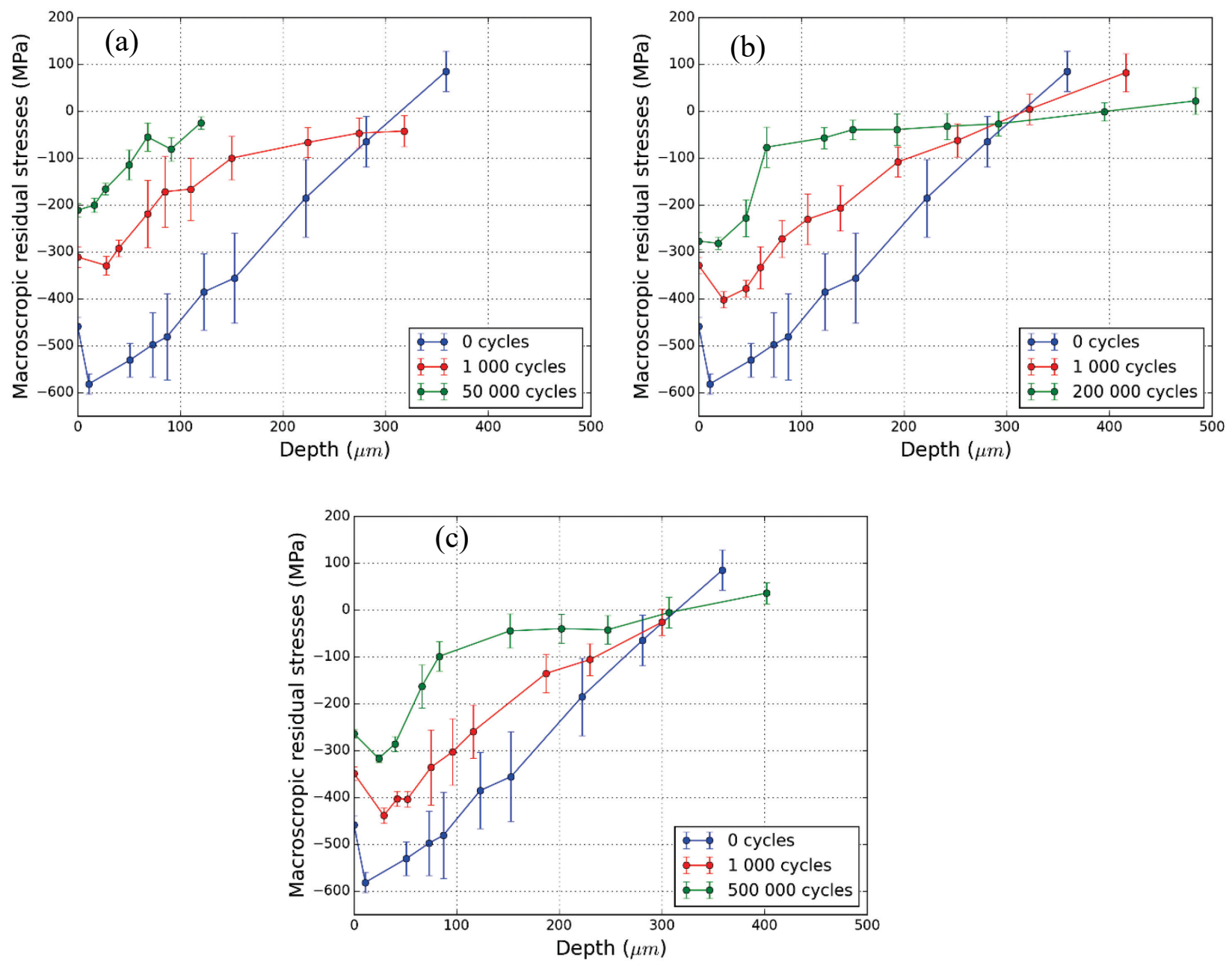

Figure 4 Relaxation for different cyclic bending loads (a) $650 \mathrm{MPa}$ (b) $600 \mathrm{MPa}$ (c) $585 \mathrm{MPa}$ $(R=-1)$.

\section{Simulation}

In this part, finite element (FE) simulations are carried out in order to understand the role of the material behavior and of the structural effect on the relaxation of a shot peened specimen. The simulations are performed with Abaqus 6.13/Standard FE software.

The first step is to model the initial mechanical state after shot-peening. Besides compressive residual stresses, shot-peening generates an important hardening at the samples surface. As a first approximation, the residual stresses are generated by the fictitious thermal method [9]. It consists in introducing fictitious dilatation coefficients $\alpha$ in a partitioned part, apply a fictive thermal load $\Delta \mathrm{T}$ which generate residual stresses due to incompatible plastic strains. Plastic strain values associated with the targeted residual stresses are obtained by equation (2) (semi-infinite body hypothesis) [8]: 
$\underline{\underline{\epsilon}} \underline{\underline{\mathrm{p}}}(\mathrm{z})=\frac{v-1}{\mathrm{E}} \sigma_{\text {res }}(\mathrm{z})$

In the hypothesis of an orthotropic residual stress state, dilatation coefficients are given by the following equation [9]:

$\underline{\underline{\alpha}}(\mathrm{z})=-\frac{2 \mu+\mathrm{C}+\mathrm{K}(\mathrm{z})}{2 \mu \cdot \Delta \theta} \cdot \underline{\underline{\epsilon}}^{\mathrm{p}}(\mathrm{z})$

with $\mathrm{K}(\mathrm{z})=\left|\frac{\sigma_{\mathrm{y}}}{3 \epsilon_{\mathrm{xx}}^{\mathrm{p}}(\mathrm{z})}\right|$

and $\mathrm{C}$ is kinematic hardening slope, $\sigma_{\mathrm{y}}$ the yield strength, and $\Delta \theta$ the imposed temperature change.
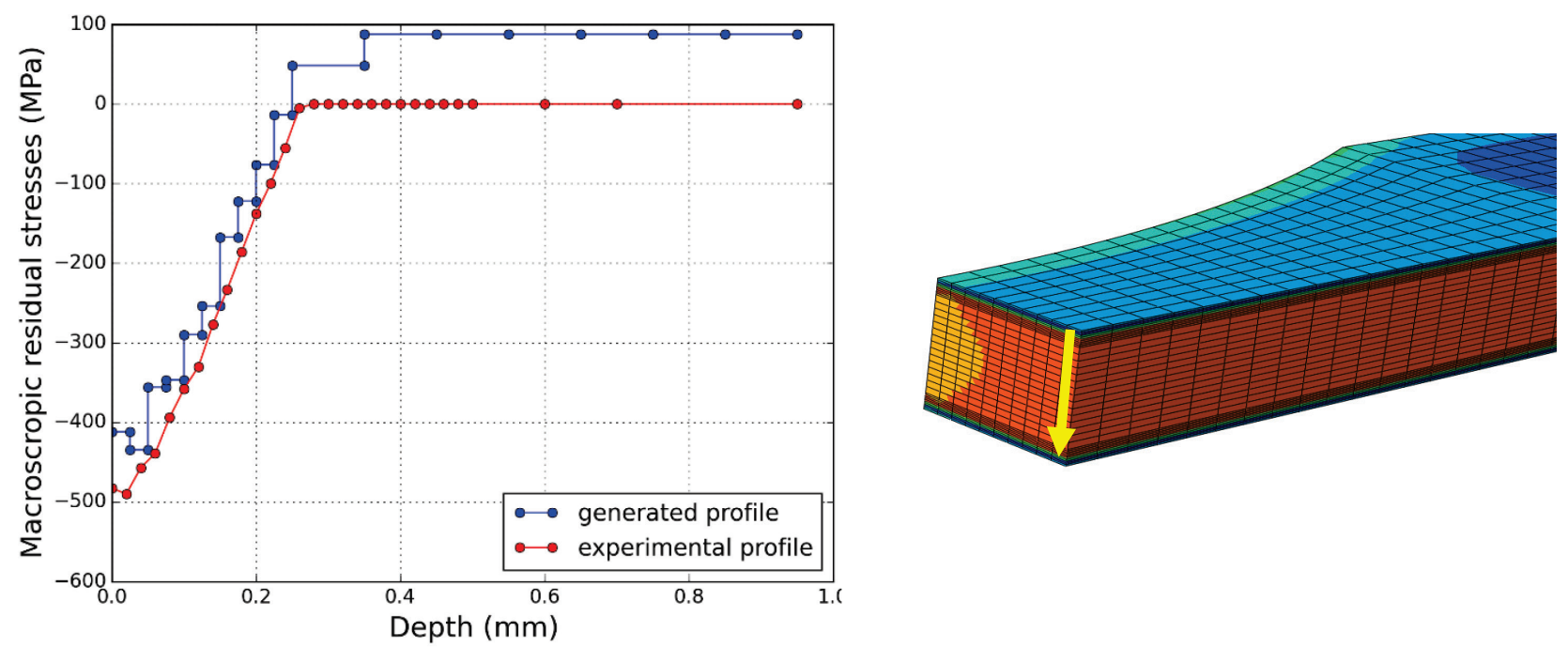

Figure 5 Simulated macroscopic residual stresses profile after shot peening and sample geometry and mesh (symmetry simplification).

The fictitious thermal method is applied to a FE model of the specimen to generate the residual macroscopic stress profile (figure 5) based on experimental data. The generated stress is slightly different from the experimental one. Indeed, the experimental profile is not self-balanced.

This method generates only the required plastic strain to generate the residual stress profile. They are about $0.3-0.4 \%$ which is far below the real plastic strain in shot-peened material (until 30-50\%). The aim of this method is not to initiate the hardening internal variables. Todo so, the yield strength $\sigma_{\mathrm{y}}$, could be change with depth in order to model some hardening effects.

Mechanical relaxation is separated in two parts [10]. Static relaxation occurs in the first bending cycles due to macroscopic strain by the superposition of residual stresses and loading. This phenomenon is modelled by a cyclic hardening law on the first 5 cycles of loading. Some numerical investigations are also presented for a material modelled with standard phenomenological constitutive laws with different hardenings.

The second part is the dynamic relaxation which needs another description of the damage mechanisms occurring at high number of cycles. 


\section{Conclusions}

The initial state of shot-peened TRIP steel and the stress relaxation under 3 reverse bending loads were investigated in this study. This experimental work is followed by FE simulations which aim to dissociate static and cyclic relaxation.

\section{References}

[1] Cooman, B. D. (2004), 'Structure and properties relationship in TRIP steels containing carbide-free bainite, Current Opinion in Solid State and Materials Science 8, 285 - 303. http://dx.doi.org/10.1016/j.cossms.2004.10.002

[2] Bleck, W. (2002), 'Using the TRIP effect-the dawn of a promising group of cold formable steels', TRIP aided high strength ferrous alloys, 13--22.

[3] Fu, P. \& Jiang, C. (2014), 'Residual stress relaxation and micro-structural development of the surface layer of 18CrNiMo7-6 steel after shot peening during isothermal annealing', Materials and Design 56, 1034--1038. http://dx.doi.org/10.1016/j.matdes.2013.12.011

[4] Ackermann, S.; Kulawinski, D.; Henkel, S. \& Biermann, H. (2014), 'Biaxial in-phase and out-of-phase cyclic deformation and fatigue behavior of an austenitic TRIP steel', International Journal of Fatigue 67(0), 123 - 133. http://dx.doi.org/10.1016/j.ijfatigue.2014.02.007

[5] EN, NF15305 Avril 2009. Essais non-destructifs: méthode d'essai pour l'analyse des contraintes résiduelles par diffraction des rayons X. AFNOR.

[6] ASTM, E. (2003). 975-03. Standard Practice for X-Ray Determination of Retained Austenite in Steel with Near Random Crystallographic Orientation.ASTM Internacional.

[7] Moore, M. G., \& Evans, W. P. (1958). Mathematical correction for stress in removed layers in X-ray diffraction residual stress analysis (No. 580035). SAE Technical Paper.

[8] Zarka, J., Frelat, J., Inglebert, G., \& Kasmai- Navidi, P. (1990). A new approach to inelastic analyses of structures.

[9] Ahdad, F.; Desvignes, M.; Castex, L.; Journet, B.; Pons, G.; Ericsson, T. \& AHMAD, M. (1995), 'Preision de la duree de vie d'une structure precontrainte: application au grenaillage', Materiaux et techniques 83(10-11), 13--18.

[10] Holzapfel, H., Schulze, V., Vöhringer, O., \& Macherauch, E. (1996). Stability and relaxation behaviour of shot peening induced residual stresses in AISI 4140 during bending fatigue. In Proc. 6th Int. Conf. on Shot Peening, San Francisco (pp. 413-423). 